Reserch Paper:

\title{
Effects of Integrative Behavioral Couple Therapy on In- fertility Self-efficacy, Dyadic Adjustment, and Sexual Sat- isfaction in Infertile Couples
}

\author{
Fatemeh Vazirnia $^{1}$ (D), Javad Karimi2 ${ }^{*}$ (D), Kourosh Goodarzi ${ }^{3}$ (D), Masoud Sadeghi ${ }^{4}$ (D) \\ 1. Department of Counseling, Borujerd Branch, Islamic Azad University, Borujerd, Iran. \\ 2. Department of Psychology, School of Literature and Humanity Sciences, Malayer University, Malayer, Iran. \\ 3. Department of Psychology, Borujerd Branch, Islamic Azad University, Borujerd, Iran. \\ 4. Department of Psychology, Faculty of Literature and Humanities, Lorestan University, Khorramabad, Iran.
}

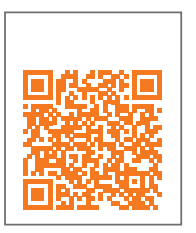

ditenton: Vazirnia, F., et al., 2021. Effects of Integrative Behavioral Couple Therapy on Infertility Self-efficacy, Dyadic Adjustment, and Sexual Satisfaction in Infertile Couples. Journal of Client-Centered Nursing Care, 7(1), pp. 43-54. https://doi. org/10.32598/JCCNC.7.1.354.1

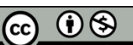

Article info:

Received: 02 Mar 2020

Accepted: 07 Sep 2020

Published: 01 Feb 2021

Keywords:

Couple therapy,

Infertility, Self-

efficacy, Psychological

adjustment, Sexual

satisfaction

\section{A B S T RA C T}

Background: Given the rising rate of infertility, the prevalence of mental health disorders in infertile couples is undeniable. The present study aimed to investigate the effects of Integrative Behavioral Couple Therapy (IBCT) on infertility self-efficacy, dyadic adjustment, and sexual satisfaction in infertile couples.

Methods: The present single-case experimental study used a multiple-baseline design. The statistical population of the study included all infertile couples referring to infertility centers in Ahvaz City, Iran, in 2019. The research instruments included the Infertility Self-Efficacy Scale (ISE), the Dyadic Adjustment Scale (DAS), and the Sexual Satisfaction Questionnaire (SSQ). Following a diagnostic interview, 3 couples were selected using convenience sampling technique. Integrative behavioral couple therapy was conducted in twelve 120-minute sessions for the intervention group. The second couple entered the study in the second session of the first couple; the third couple enrolled the treatment plan in the third session of the first couple and the second session of the second couple. All questionnaires were completed in the first, third, sixth, eighth, and tenth sessions; the study participants were followed up and re-assessed two months later. The collected data were analyzed in SPSS using chart analysis, reliable change index, and significance statistics.

Results: The provided IBCT increased infertility self-efficacy (39.04\%), dyadic adjustment (25.91\%), and sexual satisfaction (55.01\%) in infertile couples. Besides, the improvement lasted throughout the follow-up which indicated the effectiveness of IBCT on infertility self-efficiency, dyadic adjustment, and sexual satisfaction in the study subjects.

Conclusion: IBCT helps solve marital problems and is an effective method to improve personal and marital aspects are infertile couples.

\section{"Corresponding Author:}

Javad Karimi, PhD.

Address: Department of Psychology, School of Literature and Humanity Sciences, Malayer University, Malayer, Iran.

Tel: +98 (81) 33339841

E-mail:j.karimi@malayeru.ac.ir 


\section{Highlights}

- Integrative behavioral couple therapy effectively improves infertility self-efficacy in the infertile couples.

- Integrative behavioral couple therapy improved dyadic adjustment in the infertile couples.

- Integrative behavioral couple therapy increased sexual satisfaction in the infertile couples.

\section{Plain Language Summary}

Infertility is a stressful and unexpected shock for most couples. The stressful experience of infertility is associated with various psychological issues, including increased stress levels, depression, feelings of inefficiency, and marital problems. Infertile couples need to eliminate mental weaknesses and psychological traumas; therefore, strengthening positive psychological characteristics may prove effective in this regard. Integrative behavioral couple therapy is among the most important intervention programs. In general, this study suggested that integrative behavioral couple therapy is effective in improving infertility self-efficacy, dyadic adjustment, and sexual satisfaction in infertile couples.

\section{Introduction}

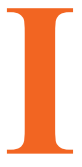

nfertility can trigger numerous psychological problems in infertile couples. The stressful experience of infertility is associated with various psychological issues, including increased levels of stress, anxiety, depression, anger, feelings of inefficiency, sexual dysfunction, and marital problems, as well as cognitive and emotional complications (Loftus \& Namaste 2011). Infertility is a stressful and unexpected shock for most couples; some types of infertility are associated with stress (Keshavarz et al. 2018). Besides, a key point in evaluating infertile couples is their sexual functioning and sexual disorders. A desirable sexual relationship may increase fertility. It is assumed that psycho-sexual problems are more common in infertile couples (Sudha, Reddy \& Reddy 2011) Moreover, sexual dysfunction and dissatisfaction are the consequences of infertility (Starc et al. 2019).

Couples experiencing infertility long after marriage present a much lower level of psychological wellbeing, compared to couples with normal fertility (Shreffler et al. 2020). Infertility and poor psychological wellbeing contribute to numerous problems, like lack of independence and ineffective communication with the spouse. Infertile couples may encounter various emotional disorders, particularly emotional inefficiency (Grunberg, Miner \& Zelkowitz 2020). It is essential to treat infertile couples. This is because in addition to physical infertility in wife or husband, there exist unaddressed psychological problems which overshadow their marital life and create multiple psychological problems for them (Patel, Venkata Narasimha Sharma \& Kumar 2020).

Infertility self-efficacy is a psychological construct that can be addressed based on infertile couples' reasons and conditions. Self-efficacy is a specific construct of infertility in couples, i.e. essential in improving their reproductive health. The theory of self-efficacy suggests that individuals with high self-efficacy present further control over the environment and in coping with difficult situations and challenging goals (Bashtian et al. 2018). They are confident that perseverance and applying solutions to problems may strengthen their self-efficacy (Altiparmak \& Derya 2018; Aziznejad et al. 2019). Selfefficacy beliefs reduce the influence of stressful situations. Besides, they are associated with reduced stress and negative emotions. Therefore, self-efficacy is a critical characteristic to cope with infertility (Ebrahimifar et al. 2018). Numerous studies reported a decline in the self-efficacy of infertile women due to low self-esteem (Zare, Bahrami \& Soleimani 2014; Moghaddam Tabrizi \& Feizbakhsh 2015), high levels of stress (Ebrahimifar et al. 2018), poor mindfulness, and emotional intelligence (Heidari \& Latifnejad 2010), poor psychological wellbeing (Mazaheri \& Bahramian 2016), and poor mental health (Hosseini et al. 2018). Therefore, therapies designed to improve self-efficacy are closely associated with self-esteem, stress reduction, mindfulness, emotional intelligence, psychological wellbeing, and mental health.

Dyadic adjustment contributes to successful interaction between couples. It can also be regarded as an adaptive behavior that allows individuals to understand and 
comply with environmental differences and act flexibly in the face of differences (Chaves, Canavarro \& Moura-Ramos 2019). Marital adjustment can help reduce marital conflicts and increase couples' adaptability by generating an evolutionary process in their relationships (Mohammadi et al. 2020; Kroemeke \& Kubicka 2018). This process can foster individuals' adjustment, adaptation, and transformation. It could also improve couples' communication and interaction patterns to achieve maximum life satisfaction. However, marital adaptation is quite poor among infertile couples. This is due to infertility issues which can attenuate their participation in the treatment process and even lead to their separation (Jamalnik, Falsafinejad \& Khodabakhshi-Koolaee 2020; Péloquin et al. 2018). Some consequences of the lack of dyadic adjustment in infertile couples include couples blaming each other (Péloquin et al. 2018), emotional weakness (Patel et al. 2018), poor self-participation (Santerre-Baillargeon et al. 2018), poor thinking styles (Mirghafourvand, Farshbaf-khalili \& Ghanbari-Homayi 2016), poor quality of marital relationships and social support (Teimourpour et al. 2015), high stress, low compassion and self-judgment (Izadi \& Sajjadian, 2017), severely negative body image (Heidari \& Latifnejad, 2010), strong dysfunctional beliefs (Fooladi et al. 2006), as well as poor coping styles and neuroticism (Hosseini et al. 2018). Numerous studies revealed the adverse impact of infertility on dyadic adjustment and sexual function (Monga 2011), anxiety, depression, and decreased quality of marital life (Peterson, Newton \& Rosen 2003). Koraei, Dasht Bozorgi and Zahery Abdh Vand (2018) indicated that the quality of marital relations plays a mediating role in coping strategies concerning stress and adjustment with infertility in infertile women.

Integrative Behavioral Couple Therapy (IBCT) is an approach to diminish the negative impact of psychological traits (Christensen, Dimidjian \& Martell 2015). Couple therapy is a strategy to solve the problems and conflicts of couples who fail to do so. IBCT is an acceptance-based approach that allows vulnerable emotions to be released while develops empathy among participants (Roddy et al. 2016). Therefore, higher levels of acceptance decrease conflicts among couples. IBCT may prove efficient in reducing marital problems and infertility-induced damages by accepting differences in couples (Baucom et al. 2015). Different studies were conducted on integrative behavioral therapy and its various effects on marital life, including increased communication beliefs in divorce-seeking couples; reduced communication issues, and psychological problems (Fischer, Baucom \& Cohen 2016); increased quality of life (Moradi \& Chardavoli 2016); enhanced marital satisfaction, im- proving couple's decision-making (Downs et al. 2018); improved marital commitment (Karimian et al. 2017), and resolving conflicts in the female victims of spousal violence (Soudani et al. 2015).

Infertile couples need to eliminate mental health conditions; therefore, strengthening positive psychological characteristics may be effective in this regard. However, no specific psychotherapy for infertile couples was found in domestic and international studies. Accordingly, this study aimed to investigate the effects of IBCT on infertility self-efficacy, dyadic adjustment, and sexual satisfaction in infertile couples.

\section{Materials and Methods}

The present Single-Case Experimental Design (SCED) study used a multiple-baseline design. SCED methodology aims to test the effectiveness of an intervention or to compare the relative effectiveness of two or more interventions. In general, Small-N designs (i.e. SCEDs) are practical complements to larger $\mathrm{N}$ trials. They can be useful in the early developmental phase of research, as well as in refining the application of research findings to individual patients. The term SCED refers to a set of experimental methods that can be used to test the effectiveness of an intervention using a small number of patients (typically 1 to 3 ). Besides, it involves repeated measurements, the sequential ( \pm randomized) introduction of an intervention, specific data analysis, and statistics. The term SCED does not cover case reports, but studies are carefully designed before the onset of an intervention; therefore; they are of experimental designs (Krasny-Pacini \& Evans 2018). The advantage of this design is that changes occur only when the therapeutic intervention focuses on behaviors or individuals.

This project compared the rate of symptom improvement during treatment in the study participants and among other participants concerning the baseline data. The statistical population of the study included all infertile couples referring to infertility centers in Ahvaz City, Iran, in 2019. The research sample consisted of 3 infertile couples who were selected by convenience sampling technique. The inclusion criteria of the study were as follows: voluntary attendance in the study, availability if retest required, having $\geq 4$ years of living together experience, having a minimum secondary education, and the attendance of both spouses in couple therapy sessions. The exclusion criteria included receiving any couple therapy before conducting the study, having a serious medical disorder that interferes with the study procedure, and absence from $>2$ treatment sessions. For 
ethical considerations, the researchers received written informed consent forms from the study samples for participation in this research.

The instruments applied in the present research to collect the necessary data were as follows:

The Infertility Self-Efficacy Scale (ISE): The ISE was developed by Cousineau et al. (2006) to assess the infertile patients' perception of their ability to use their behavioral, emotional, and cognitive abilities for coping with the infertility diagnosis and medical treatment. It has 16 items and answers are scored on a 9-point Likerttype scale, ranging from strongly disagree (1) to strongly agree (9). The Persian version of this scale was translated and validated by Ebrahimifar et al. (2018). In the Persian version of the scale, answers were scored on a 5-point Likert-type scale, ranging from strongly disagree (1) to strongly agree (5). The overall score ranges from 16 to 80 , where higher scores indicate a greater degree of infertility self-efficacy. Galhardo, Cunha and PintoGouveia (2013) reported a Cronbach's alpha coefficient of 0.96 for the questionnaire. In Iran, the internal consistency of the questionnaire was calculated as 0.90 using Cronbach's alpha coefficient (Ebrahimifar et al. 2018). In the present study, Cronbach's alpha coefficient was measured as 0.80 .

Dyadic Adjustment Scale (DAS): The DAS was created by Spanier in 1976 and measures global marital adjustment (Abedi et al. 2014). It is a 32-item scale to measure the quality of marital relations; the DAS includes the dimensions of marital satisfaction (10 items), mutual solidarity (5 items), mutual agreement (13 items), and expression of love (4 items). All items are scored on a 6-point Likert-type scale, ranging from 0 to 5, except for items 23 and 24 , i.e. scored on a 5-point Likert-type scale, ranging from 0 to 4 . The overall score ranges from 0 to 151 , where higher scores indicate more positive dyadic adjustment. In a study, the Cronbach's alpha coefficient of DAS was calculated to be 0.85 (Abedi et al. 2014). In the present study, Cronbach's alpha coefficient was computed as 0.83 .

Sexual Satisfaction Questionnaire (SSQ): The SSQ was developed by Larson in 1988. It has 25 items and 4 components of libido (5 items), sexual attitude (6 items), quality of sexual life ( 8 items), and sexual adjustment (6 items) (Bahrami et al. 2010). It is scored on a 5-point Likert-type scale from Never $=1$ to Always $=5$. Total scores can range from 1 to 125 , with higher scores reflecting further sexual satisfaction. Bahrami et al. (2010) reported an alpha Cronbach coefficient of 0.93 for the questionnaire. In the present study, Cronbach's alpha coefficient was measured to be 0.85 .

In two months, following a diagnostic interview conducted by the first author and identifying eligible couples, 3 couples who met the inclusion criteria were selected using the convenience sampling method. To conduct the therapy, the first couple entered the treatment plan, and at each baseline stage, all research instruments were used for the first couple at baseline. The first, second, and third couples were assessed twice, thrice, and four times, respectively. IBCT was conducted in twelve 120-minute sessions according to the relevant therapeutic package (Perissutti \& Barraca, 2013). To control the extraneous and potentially intervening variables according to the principles of multiple baseline designs, the second couple entered the study in the second session of the first couple; the third couple enrolled the treatment plan in the third session of the first couple and the second session of the second couple. All the questionnaires were completed in the first, third, sixth, eighth, and tenth sessions; the study participants were followed up and re-assessed two months later.

IBCT was developed by Jacobson and Christensen based on the Traditional Behavioral Couples Therapy (TBCT) (Perissutti \& Barraca 2013). This is a contextually based treatment that helps couples increase their satisfaction and compatibility. The intervention sessions were conducted by the first author in a psychotherapy center in Ahvaz. Table 1 presents a summary of the IBCT sessions.

The collected data were analyzed in SPSS V. 21 using chart analysis and Reliable Change Index (RCI). RCI is a concept in measurement and assessment. An RCI is a psychometric criterion used to evaluate the changes of an individual score over time (i.e. the difference in scores between two measurements in time), i.e. considered statistically significant. RCI is computed by dividing the difference between the pretreatment and posttreatment scores by the standard error of the difference between the two values (Guhn, Forer \& Zumbo 2014).

\section{Results}

Two study participants had a diploma and 4 had academic education. Four research participants were employees and 2 were housewives. The mean age of the study participants and average duration of their marriage was 34 and 8.6 years, respectively. Tables 2, 3 and 4 indicate the scores of ISE, DAS, and SSQ for all investigated couples at the baseline, treatment, and follow-up stages 
Table 1. A summary of the integrative behavioral couple therapy sessions

\begin{tabular}{|c|c|c|}
\hline Content & Session & Objectives-Assignments \\
\hline & First & $\begin{array}{l}\text { Objectives: Introduction, a summary of demographic data, couples' therapy mission, } \\
\text { stating the principles of therapy sessions } \\
\text { Assignments: Giving complaints, stating objectives and related issues, discussing pri- } \\
\text { mary attractions }\end{array}$ \\
\hline Assessment & Second \& Third & $\begin{array}{l}\text { Objectives: Hosting individual meetings with couples, expressing the principles of con- } \\
\text { fidentiality, overcoming current problems based on scales and the first interview, re- } \\
\text { viewing issues related to violence and commitment, reviewing the history of the main } \\
\text { family, reviewing the history of communication, conducting the pre-test } \\
\text { Assignments: Completing the questionnaires and discussing emotional sensitivities and } \\
\text { external stresses, expressing views on commitment, and continuing the relationship }\end{array}$ \\
\hline \multirow[t]{2}{*}{ Feedback \& Formulation } & Fourth \& Fifth & $\begin{array}{l}\text { Objectives: Providing feedback to the couples, providing vision and formulating prob- } \\
\text { lems, identifying major issues and problems (trust, depression, post-traumatic stress, } \\
\text { etc.), identifying the strengths of the relationship } \\
\text { Assignments: Reading the brochures prepared for depression, discussing the thera- } \\
\text { pist's views and formulation and their compliance with the couples' opinions }\end{array}$ \\
\hline & Sixth & $\begin{array}{l}\text { Objectives: Discussing interactive patterns, interventions to prevent, interrupt, redi- } \\
\text { rect, or limit problematic interactions } \\
\text { Assignments: Summarizing other couples' messages, focusing on the experiences here } \\
\text { and now, couples' relationship with each other through the therapist }\end{array}$ \\
\hline \multirow{4}{*}{ Intervention } & Seventh \& Eighth & $\begin{array}{l}\text { Objectives: Emotion-focused intervention (for empathetic integration) } \\
\text { Assignments: Identifying primary emotions, revealing emotions, role-playing to ex- } \\
\text { press emotions, focusing on emotions instead of thoughts, empathizing with each } \\
\text { other's feelings }\end{array}$ \\
\hline & Ninth \& Tenth & $\begin{array}{l}\text { Objectives: Behavior-based interventions (to improve behavior) } \\
\text { Assignments: Repeating interactions in the meeting, exchanging behaviors, practicing } \\
\text { communication skills }\end{array}$ \\
\hline & Eleventh & $\begin{array}{l}\text { Objectives: Tolerance-building interventions } \\
\text { Assignments: Practicing negative behaviors, listing measures for self-care }\end{array}$ \\
\hline & Twelfth & $\begin{array}{l}\text { Objectives: Summarizing, helping couples to cope with stressors, running the post-test } \\
\text { Assignments: Discussing therapeutic achievements and deciding for the future, com- } \\
\text { pleting the post-test }\end{array}$ \\
\hline
\end{tabular}

Client- Centered Nursing Care

( 2 to 4 times at baseline, 5 times at intervention, \& 2 times at follow-up) along with reliable change index and improvement rate by various stages of treatment.

Based on Table 2, the scores of infertility self-efficacy significantly increased in the treatment phase (39.04\%). Besides, this improvement lasted throughout the followup $(48.74 \%)$, indicating the effectiveness of the IBCT in infertility self-efficiency.

Dyadic adjustment scores significantly increased during the treatment phase $(25.91 \%)$. The improvement lasted throughout the follow-up (26.46\%), reflecting the effectiveness of the IBCT on dyadic adjustment (Table 3).

According to Table 4, the scores of sexual satisfaction significantly increased in the treatment phase (55.01\%). Furthermore, such an improvement lasted till the followup step (56.17\%), highlighting the effectiveness of the
IBCT on sexual satisfaction. The changes in infertility self-efficacy, dyadic adjustment, and sexual satisfaction scores at the baseline, intervention, and follow-up phases are presented in Figure 1.

\section{Discussion}

The present study assessed the effects of IBCT on infertility self-efficacy, dyadic adjustment, and sexual satisfaction in infertile couples. The obtained results indicated an optimal and effective improvement in the scores of infertility self-efficacy, dyadic adjustment, and sexual satisfaction in all studied couples. These results were consistent with those of Ahmadi et al. (2019), Dargahi et al. (2018), and Soleimani et al. (2015).

Infertile couples lack empathetic solidarity about their infertility and cannot accept that empathetic improvement will essentially impact their behavior in this re- 
Table 2. The trends of the effects of changing the treatment phases of infertile couples on the infertility self-efficacy scale

\begin{tabular}{|c|c|c|c|}
\hline Treatment Phases & The First Couple & The Second Couple & The Third Couple \\
\hline First baseline & 45.50 & 41.00 & 36.00 \\
\hline Second baseline & 45.50 & 39.50 & 35.50 \\
\hline Third baseline & - & 39.00 & 37.00 \\
\hline Fourth baseline & - & - & 38.00 \\
\hline Mean & 45.50 & 39.80 & 36.60 \\
\hline First session & 56.00 & 51.00 & 50.00 \\
\hline Third session & 57.00 & 53.00 & 59.00 \\
\hline Sixth Session & 51.00 & 56.00 & 58.00 \\
\hline Eighth Session & 68.00 & 60.00 & 55.00 \\
\hline Tenth session & 62.00 & 55.00 & 52.00 \\
\hline Mean & 58.80 & 55.00 & 54.80 \\
\hline Reliable change index (treatment) & 2.03 & 2.18 & 2.42 \\
\hline Improvement rate posttreatment (\%) & 29.23 & 38.07 & 49.62 \\
\hline Mean (\%) & & 39.04 & \\
\hline First follow-up & 59.00 & 62.00 & 59.00 \\
\hline Second follow-up & 61.00 & 61.00 & 58.00 \\
\hline Mean & 60.00 & 61.50 & 58.50 \\
\hline Reliable change index (follow-up) & 2.13 & 2.69 & 2.70 \\
\hline Improvement rate after follow-up (\%) & 31.86 & 54.52 & 59.83 \\
\hline Mean (\%) & & 48.74 & \\
\hline
\end{tabular}

gard (Klitzman 2018). According to the IBCT method, couples should express their thoughts and feelings about their problem; thoughts that evoke defensive, unacceptable, or unreliable responses, or negative behaviors should be considered as normal differences between individuals; infertility should not be considered a major problem that dissuades couples from continuing their married life. Accordingly, couples learn to perceive their spouse's behaviors as temporary and never find negative behaviors as constant (Christensen \& Glynn 2019). Furthermore, they are both responsible for coping with problems and should take advantage of each other's integrated approach to the complication. This is called integrative withdrawal which helps couples discuss their problems, instead of directly getting involved with the problem. Tolerance-Building is a strategy to improve positive retrospective relationships and reduce negative behaviors and believes that there exist positive points in couples besides their infertility (Pasch \& Sullivan 2017).

Furthermore, this technique teaches communication skills and solves the antithesis of behavioral exchange problems, i.e. no emphasis on current complications. Short-term changes in the ratio of positive to negative behaviors are ignored. Instead, couples learn to be their therapist through learning communication and conflict resolution skills (Lemmens et al. 2004). Changes made through communication and problem-solving skills training are slower but more lasting than those made through the behavioral exchange. Behavioral exchange, communication skills, and problem-solving skills training are expected to present positive and lasting effects together. Through the IBCT, couples learn to improve their behavior towards problems. This enables them to modi- 
Table 3. The trends of the effects of changing the treatment phases of infertile couples on the dyadic adjustment scale

\begin{tabular}{|c|c|c|c|}
\hline Treatment Phases & The First Couple & The Second Couple & The Third Couple \\
\hline First baseline & 80.00 & 84.00 & 89.00 \\
\hline Second baseline & 80.00 & 83.00 & 87.00 \\
\hline Third baseline & - & 86.00 & 85.00 \\
\hline Fourth baseline & - & - & 87.00 \\
\hline Mean & 80.00 & 84.33 & 87.00 \\
\hline First session & 110.00 & 105.00 & 111.00 \\
\hline Third session & 112.00 & 109.00 & 120.00 \\
\hline Sixth Session & 110.00 & 104.00 & 123.00 \\
\hline Eighth Session & 119.00 & 111.00 & 121.00 \\
\hline Tenth session & 115.00 & 109.00 & 119.00 \\
\hline Mean & 113.20 & 107.60 & 118.80 \\
\hline Reliable change index (treatment) & 2.85 & 2.86 & 2.88 \\
\hline Improvement rate posttreatment (\%) & 29.33 & 21.62 & 26.77 \\
\hline Mean (\%) & & 25.91 & \\
\hline First follow-up & 114.00 & 109.00 & 115.00 \\
\hline Second follow-up & 115.00 & 110.00 & 121.00 \\
\hline Mean & 114.50 & 109.50 & 118.00 \\
\hline Reliable change index (follow-up) & 3.54 & 10.98 & 7.72 \\
\hline Improvement rate after follow-up (\%) & 30.13 & 22.98 & 26.27 \\
\hline Mean (\%) & & 26.46 & \\
\hline
\end{tabular}

fy their inappropriate feelings, interpersonal relationship behaviors, as well as their problematic situations. Therefore, marital non-adjustment in infertile couples reduces, and they can experience infertility self-efficacy (Vernon 2012). In this technique, couples learn to reduce the odds of post-problem behaviors when encountering smaller persisting problems along with infertility. Therefore, they are encouraged to ignore unpleasant thoughts that make them upset during infertility treatment. This is because they are transient and fade away in posttreatment situations (Pasch \& Sullivan 2017).

The IBCT benefits empathetic solidarity on the problem, united impartiality in examining the problem, increased tolerance when facing a problem, and enhanced self-care activities when encountering unresolved problems to improve emotional acceptance between couples (Faghih \& Kazemi 2019). The obtained results suggested that IBCT could improve conflict resolution tactics in infertile couples and increase their adjustment. Techniques, such as pretending to have negative behaviors significantly reduce couples' aggression, which diminishes dyadic adjustment, and pretending to be negative makes them aware of their behaviors. Increased awareness automatically reduces problematic behavior (Christensen \& Glynn 2019). Communication and problem-solving skills training addressed in IBCT may be effective in the occurrence and prevention of violence. For example, teaching active listening, teaching emotional expression, using the "I" pronoun, and identifying and removing communication barriers, help reduce accusations, humiliation, disrespect, and extreme generalizations. Consequently, differences are managed through 
Table 4. The trend of the effects of changes in the treatment phases of infertile couples on the sexual satisfaction scale

\begin{tabular}{|c|c|c|c|}
\hline Treatment Phases & The First Couple & The Second Couple & The Third Couple \\
\hline First baseline & 41.00 & 42.00 & 41.00 \\
\hline Second baseline & 40.00 & 40.00 & 33.00 \\
\hline Third baseline & - & 39.00 & 35.00 \\
\hline Fourth baseline & - & - & 38.00 \\
\hline Mean & 40.50 & 40.33 & 36.75 \\
\hline First session & 95.00 & 89.00 & 84.00 \\
\hline Third session & 91.00 & 88.00 & 85.00 \\
\hline Sixth Session & 81.00 & 87.00 & 94.00 \\
\hline Eighth Session & 87.00 & 89.00 & 90.00 \\
\hline Tenth session & 87.00 & 70.00 & 91.00 \\
\hline Mean & 88.20 & 84.60 & 88.80 \\
\hline Reliable change index (treatment) & 2.84 & 2.08 & 2.90 \\
\hline Improvement rate posttreatment (\%) & 54.08 & 52.32 & 58.61 \\
\hline Mean (\%) & & 55.01 & \\
\hline First follow-up & 89.00 & 88.00 & 91.00 \\
\hline Second follow-up & 88.00 & 89.00 & 92.00 \\
\hline Mean & 88.50 & 88.50 & 91.50 \\
\hline Reliable change index (follow-up) & 3.54 & 2.84 & 2.09 \\
\hline Improvement rate after follow-up (\%) & 54.24 & 54.43 & 59.84 \\
\hline Mean (\%) & & 56.17 & \\
\hline
\end{tabular}

negotiation instead of resolving conflicts through aggression (Christensen \& Doss 2017).

The provided IBCT improved the sexual satisfaction of the research subjects. This result is consistent with those of Soleimani et al. (2015). Due to biopsychological changes, couples encounter numerous issues during infertility, especially in their marital relationships. IBCT could effectively increase positive reinforcement. The purpose of behavioral activation is to encourage behaviors, i.e. likely to receive rewards from the patient which could be intrinsic (e.g. pleasure or a sense of accomplishment) or extrinsic (e.g. social attention). Boosting rewards first helps to improve the patients' mood and ultimately improves their marital relationships and intimacy. Then, it improves social relationships and receiving positive reinforcements, which in turn, promotes marital intimacy (Vizheh et al. 2013). Be- havioral activation uses the strategy of breaking difficult tasks into smaller steps and elements (Dargahi et al. 2018). As a result, using this approach, individuals progressively learn activities that lead to positive reinforcement. In this method, therapy seekers also learn to identify their avoidance behaviors and use alternative coping strategies to approach and get engaged in issues. This increases their sexual satisfaction by improving their relationship with their spouse (Soleimani et al. 2015).

\section{Conclusion}

IBCT is an appropriate approach to improve infertility self-efficacy, dyadic adjustment, and sexual satisfaction in infertile couples. IBCT can also increase the couples' ability to interact with infertility during infertility treatment. Based on the present study findings, couple thera- 


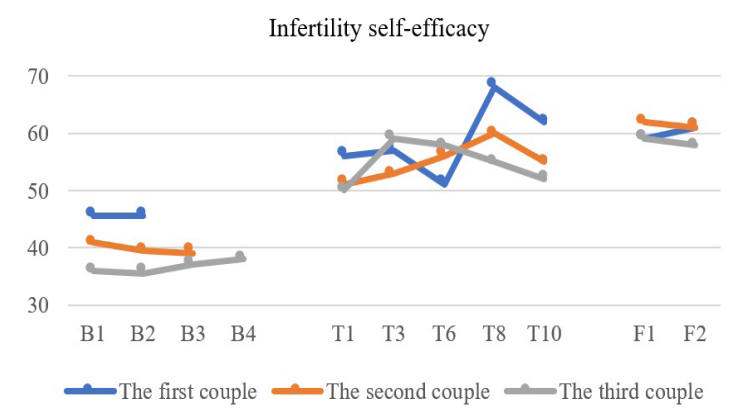

(a)

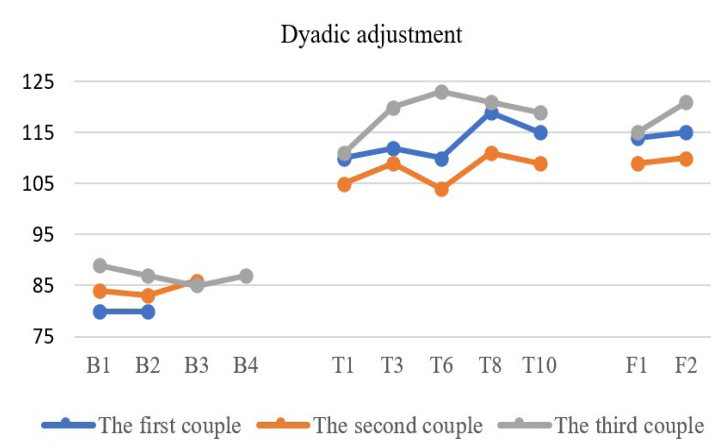

(b)

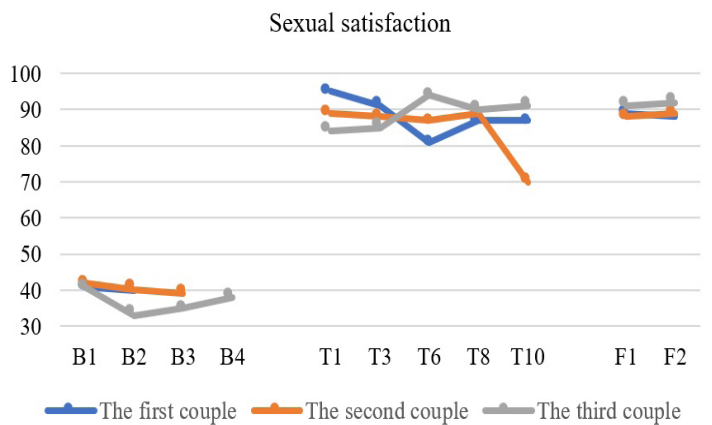

(c)

Figure 1. The changes in infertility

A: The trend of infertility self-efficacy; B: Dyadic adjustment; and C: Sexual satisfaction scores at the baseline, intervention, and follow-up phases among the study subjects

pists and infertility therapists and counselors can improve the infertility self-efficacy of infertile couples by IBCT and emotion-based couple therapy. Midwives can introduce this intervention program to infertile couples. Furthermore, psychiatric nurses can cooperate in evaluating these couples and implementing the technique. Performing the same study by other research designs is suggested.

\section{Ethical Considerations}

\section{Compliance with ethical guidelines}

This study was approved by Ethics Committee of Islamic Azad University, Borujerd Branch (Code: IR.IAU.B.REC.1398.014). All ethical principles are considered in this article. The participants were informed about the purpose of the research and its implementation stages. They were also assured about the confidentiality of their information and were free to leave the study whenever they wished, and if desired, the research results would be available to them.
Funding

This study was extracted by the $\mathrm{PhD}$. dissertation first author at the Department of Counseling, Borujerd Branch, Islamic Azad University, Borujerd.

\section{Authors' contributions}

Conceptualization, supervision: Fatemeh Vazirnia, Javad Karimi; Methodology: Fatemeh Vazirnia, Kourosh Goodarzi; Investigation, writing-review \& editing: Fatemeh Vazirnia, Javad Karimi, Masoud Sadeghi. Writin original draft: Fatemeh Vazirnia, Javad Karimi, Kourosh Goodarzi, Masoud Sadeghi; Data collection: Fatemeh Vazirnia, Javad Karimi; Data analysis: Fatemeh Vazirnia, Kourosh Goodarzi; Funding acquisition, Resources: Fatemeh Vazirnia.

\section{Conflict of interest}

The authors declared no conflicts of interest. 


\section{References}

Abedi, G., et al., 2014. [The relationship between quality of life and marriage satisfaction in infertile couples using path analysis (Persian)]. Journal of Mazandaran University of Medical Sciences, 24(117), pp. 184-93. http://jmums.mazums.ac.ir/ article-1-4443-en.html

Ahmadi, S. M., et al., 2019. The effect of behavioral couple therapy on the improvement of mental health and reduction of marital conflict in infertile couples in Kermanshah: A Randomized Controlled Trial (RCT). Journal of Reproduction $\mathcal{E}$ Infertility, 20(1), pp. 16-23. [PMID] [PMCID]

Altiparmak, S., \& Derya, Y. A., 2018. The effects of fertility-supporting health training on healthy lifestyle behaviors and infertility self-efficacy in infertile women: A quasi-experimental study. European Journal of Integrative Medicine, 20, pp. 146-53. [DOI:10.1016/j.eujim.2018.05.005]

Aziznejad, M., et al., 2019. Self-awareness skill training of mothers as the head of the household and the self-efficacy of their sons. Journal of Client-centered Nursing Care, 5(4), pp. 213-22. [DOI:10.32598/JCCNC.5.4.93.7]

Bahrami, N., et al., 2010. [Relation between infertility and sexual satisfaction in couples (Persian)]. Journal of Reproduction and Infertility, 1(30), pp. 52-9. https://www.sid.ir/fa/journal/ ViewPaper.aspx?id=60471

Bashtian, M., et al., 2018. Evaluation of acupressure effects on self-efficacy and pregnancy rate in infertile women under in vitro fertilization/intracytoplasmic sperm injection treatment: A randomized controlled trial. Journal of Education and Health Promotion, 7, p. 84. [DOI:10.4103/jehp.jehp_196_17] [PMID] [PMCID]

Chaves, C., Canavarro, M. C., \& Moura-Ramos, M., 2019. The role of dyadic coping on the marital and emotional adjustment of couples with infertility. Family Process, 58(2), pp. 509-23. [DOI:10.1111/famp.12364] [PMID]

Christensen, A., \& Doss, B. D., 2017. Integrative behavioral couple therapy. Current Opinion in Psychology, 13, pp. 111-4. [DOI:10.1016/j.copsyc.2016.04.022] [PMID] [PMCID]

Christensen, A. \& Glynn, S., 2019. Integrative behavioral couple therapy. In: B. H. Fiese, et al. (eds), APA handbooks in psychology. APA handbook of contemporary family psychology: Family therapy and training, American Psychological Association, Washington, D.C.,. [DOI:10.1037/0000101-017]

Christensen, A., Dimidjian, S., \& Martell, C. R., 2015. Integrative behavioral couple therapy. In: A. S. Gurman, J. L. Lebow. \& D. K. Snyder (eds), Clinical handbook of couple therapy, Guilford Publications, New York. https://books.google.com/ books?id=WkPyCAAAQBAJ\&dq

Cousineau, T. M., et al., 2006. Development and validation of the infertility self-efficacy scale. Fertility and Sterility, 85(6), pp. 1684-96. [DOI:10.1016/j.fertnstert.2005.10.077] [PMID]

Dargahi, S., et al., 2018. Effect of behavioral-communication couple therapy in dimensions of marital adjustment in infertile couples. Journal of Research \& Health, 8(4), pp. 313-21. [DOI:10.29252/jrh.8.4.313]

Downs, J. S., et al., 2018. Video intervention to increase perceived self-efficacy for condom use in a randomized controlled trial of female adolescents. Journal of Pediatric and Adolescent Gy- necology, 31(3), pp. 291-8. [DOI:10.1016/j.jpag.2017.10.008] [PMID] [PMCID]

Ebrahimifar, M., et al., 2018. [Psychometric properties of the Persian version of the infertility self-efficacy scale (Persian)]. Research in Medicine, 42(2), pp. 100-5. https:/ / pejouhesh.sbmu. ac.ir/article-1-1817-en.html

Faghih, S., \& Kazemi, H., 2019. Effectiveness of emotionally focused couples therapy on the control of infertile couples' emotions. Journal of Holistic Nursing and Midwifery, 29(3), pp. 31-6. [DOI:10.32598/JHNM.29.3.153]

Fischer, M. S., Baucom, D. H., \& Cohen, M. J., 2016. Cognitivebehavioral couple therapies: Review of the evidence for the treatment of relationship distress, psychopathology, and chronic health conditions. Family Process, 55(3), pp. 423-42. [DOI:10.1111/famp.12227] [PMID]

Fooladi, E., et al., 2006. [Study of infertile husbands' and wives' point of view to infertility and marital adjustment in patients reffering to Royan infertility center of Tehran in 2005 (Persian)]. Journal of Mazandaran University of Medical Sciences, 16(55), pp. 131-7. http://jmums.mazums.ac.ir/article-1-162-en.html

Galhardo, A., Cunha, M., \& Pinto-Gouveia, J., 2013. Measuring self-efficacy to deal with infertility: Psychometric properties and confirmatory factor analysis of the Portuguese version of the infertility self-efficacy scale. Research in Nursing $\mathcal{E}$ Health, 36(1), pp. 65-74. [DOI:10.1002/nur.21516] [PMID]

Grunberg, P., Miner, S., \& Zelkowitz, P., 2020. Infertility and perceived stress: The role of identity concerns in treatmentseeking men and women. Human Fertility: Journal of the British Fertility Society, 5, pp. 1-11. [DOI:10.1080/14647273.2019.1709 667] [PMID]

Guhn, M., Forer, B., \& Zumbo, B. D., 2014. Reliable change index. In: A. C. Michalos (eds), Encyclopedia of quality of life and well-being research, Springer Netherlands, Dordrecht. [DOI:10.1007/978-94-007-0753-5_2465]

Heidari, P., \& Latifnejad, R., 2010. [Relationship between psychosocial factors and marital satisfaction in infertile women (Persian)]. Journal of Inflammatory Diseases, 14(1), pp. 26-32. http://journal.qums.ac.ir/article-1-922-en.html

Hosseini, M., et al., 2018. [The effectiveness of holistic-oriented psychological intervention on psychological health and pregnancy rate of unexplained infertile women undergoing IVF (Persian)]. Journal of Clinical Psychology, 25(1), pp. 59-74. [DOI:10.22055/PSY.2018.21822.1802]

Izadi, N., \& Sajjadian, I., 2017. [The relationship between dyadic adjustment and infertility-related stress: The mediated role of self-compassion and self-judgment (Persian)]. Journal of Nursing Education, 5(2), pp. 15-22. [DOI:10.21859/ijpn-05023]

Jamalnik, M., Falsafinejad, M. R., \& Khodabakhshi-Koolaee, A., 2020. Long-term marital satisfaction: Couples' narratives of the role of mate selection. Journal of Client-centered Nursing Care, 6(4), pp. 267-76. [DOI:10.32598/JCCNC.6.4.337.1]

Karimian, N., et al., 2017. [Integrative treatments, sex and couple therapy: study and comparison of the effectiveness of Integrative Behavioral Couple Therapy (IBCT) and redecision therapy in improvement of marital commitment of competing couples (Persian)]. Family Counseling and Psychotherapy, 6(2), pp. 21-38. http:// fcp.uok.ac.ir/article_44536.html?lang=en 
Keshavarz, F., et al., 2018. Coping strategies and perceived stress in infertile couples. Journal of Client-centered Nursing Care, 4(2), pp. 80-7. [DOI:10.32598/jccnc.4.2.80]

Baucom, D. H., et al., 2015. Cognitive-behavioral couple therapy. In: A. S. Gurman, J. L. Lebow, \& D. K. Snyder (eds), Clinical handbook of couple therapy, The Guilford Press, New York. https:/ / psycnet.apa.org/record/2015-25194-002

Klitzman R., 2018. Impediments to communication and relationships between infertility care providers and patients. BMC Women's Health, 18(1), p. 84. [DOI:10.1186/s12905-018-0572-6] [PMID] [PMCID]

Koraei, A., Dasht Bozorgi, Z., \& Zahery Abdh Vand, S., 2018. The effect of coping strategies on coping with infertility in women: Mediator role of marital quality. Avicenna Journal of Nursing and Midwifery Care, 26(3), pp. 191-202. [DOI:10.30699/ sjhnmf.26.3.191]

Krasny-Pacini, A., \& Evans, J., 2018. Single-case experimental designs to assess intervention effectiveness in rehabilitation: A practical guide. Annals of Physical and Rehabilitation Medicine, 61(3), pp. 164-79. [DOI:10.1016/j.rehab.2017.12.002] [PMID]

Kroemeke, A., \& Kubicka, E., 2018. Positive and negative adjustment in couples undergoing infertility treatment: The impact of support exchange. PloS One, 13(6), p. e0200124. [DOI:10.1371/journal.pone.0200124] [PMID] [PMCID]

Lemmens, G., et al., 2004. Coping with infertility: A body-mind group intervention programme for infertile couples. $\mathrm{Hu}$ man Reproduction, 19(8), pp. 1917-23. [DOI:10.1093/humrep/ deh323] [PMID]

Loftus, J., \& Namaste, P., 2011. Expectant mothers: Women's infertility and the potential identity of biological motherhood. Qualitative Sociology Review, 7(1), pp. 36-54. https://www. researchgate.net/publication/289150725_Expectant_Mothers_Women's_Infertility_and_the_Potential_Identity_of_Biological_Motherhood

Mazaheri, M., \& Bahramian, S. H., 2016. [Prediction of psychological well-being based on the positive and negative affection and coping self - efficacy (Persian)]. Positive Psychology Research, 1(4), pp. 1-14. https://ppls.ui.ac.ir/article_21047.html

Mirghafourvand, M., Farshbaf-khalili, A., \& Ghanbari-Homayi, S., 2016. [The relationship between marital adjustment and thinking styles in infertile women referred to alzahra Hospital, Tabriz- 2014 (Persian)]. Nursing and Midwifery Journal, 13(11), pp. 964-72. http://unmf.umsu.ac.ir/browse.php?a_ $\mathrm{id}=2201 \&$ sid $=1 \&$ slc_lang $=$ en

Moghaddam Tabrizi, F., \& Feizbakhsh, N., 2015. [Self-esteem, self-efficacy and treatment outcome in infertile women undergoing in vitro fertilization referring to Urmia infertility center, 2014 (Persian)]. Nursing and Midwifery Journal, 13(6), pp. 53543. http://unmf.umsu.ac.ir/article-1-2382-en.html

Mohammadi, S., et al., 2020. Effectiveness of schema therapy and emotional self-regulation therapy in the components of women's marital conflicts. Journal of Client-centered Nursing Care, 6(4), pp. 277-88. [DOI:10.32598/JCCNC.6.4.341.1]

Monga, M., 2011. Impact of infertility on quality of life, marital adjustment, and sexual function. Adult Urology, 63(1), pp. 12630. [DOI:10.1016/j.urology.2003.09.015] [PMID]

Moradi, O., \& Chardavoli, S. H., 2016. [The survey of effectiveness of couple therapy combining cognitive-behavioral with structural on aspects life's quality of couples divorced (Persian)]. Journal of Counseling Research, 15(57), pp. 24-40. http:// irancounseling.ir $/$ journal $/$ browse.php?a_id $=79 \&$ sid $=1 \&$ slc lang=en

Pasch, L. A., \& Sullivan, K. T., 2017. Stress and coping in couples facing infertility. Current Opinion in Psychology, 13, pp. 131-5. [DOI:10.1016/j.copsyc.2016.07.004] [PMID]

Patel, A., et al., 2018. Sociocultural determinants of infertility stress in patients undergoing fertility treatments. Journal of Human Reproductive Sciences, 11(2), pp. 172-9. [DOI:10.4103/ jhrs.JHRS_134_17] [PMID] [PMCID]

Patel, A., Venkata Narasimha Sharma P. S., \& Kumar, P., 2020. Psychiatric disorders in women seeking fertility treatments: A clinical investigation in India. International Journal of Fertility and Sterility, 14(1), pp. 68-71. [DOI:10.22074/ijfs.2020.5759] [PMID] [PMCID]

Péloquin, K., et al., 2018. Whose fault is it? Blame predicting psychological adjustment and couple satisfaction in couples seeking fertility treatment. Journal of Psychosomatic $\mathrm{Ob}$ stetrics \& Gynecology, 39(1), pp. 64-72. [DOI:10.1080/016748 2X.2017.1289369] [PMID]

Perissutti, C., \& Barraca, J., 2013. Integrative behavioral couple therapy vs. traditional behavioral couple therapy: A theoretical review of the differential effectiveness. Clinical and Health, 24(1), pp. 11-8. [DOI:10.5093/cl2013a2]

Peterson, B. D., Newton, C. R., \& Rosen, K. H., 2003. Examining congruence between partners' perceived infertility-related stress and its relationship to martial adjustment and depression in infertile couples. Family Process, 42(1), pp. 59-70. [DOI:10.1111/j.1545-5300.2003.00059.x] [PMID]

Roddy, M. K., et al., 2016. Integrative behavioral couple therapy: Theoretical background, empirical research, and dissemination. Family Process, 55(3), pp. 408-22. [DOI:10.1111/ famp.12223] [PMID]

Santerre-Baillargeon, M., et al., 2018. Does self-compassion benefit couples coping with vulvodynia? Associations with psychological, sexual, and relationship adjustment. The Clinical Journal of Pain, 34(7), pp. 629-37. [DOI:10.1097/ AJP.00000000000000579] [PMID]

Shreffler, K. M., et al., 2020. Is infertility resolution associated with a change in women's well-being? Human Reproduction (Oxford, England), 35(3), pp. 605-16. [DOI:10.1093/humrep/ dez297] [PMID] [PMCID]

Soleimani, A. A., et al., 2015. The effectiveness of emotionally focused couples therapy on sexual satisfaction and marital adjustment of infertile couples with marital conflicts. International Journal of Fertility and Sterility, 9(3), pp. 393-402. [DOI:10.22074/ijfs.2015.4556] [PMID] [PMCID]

Soudani, M., et al., 2015. [Comparing the effectiveness of narrative couple therapy and integrative behavior couple therapy on conflict solving tactics of female victims of violence (Persian)]. Quarterly Journal of Women and Society, 6(23), pp. 1-12. http://jzvj.miau.ac.ir/article_927.html

Starc, A., et al., 2019. Infertility and sexual dysfunctions: A systematic literature review. Acta Clinica Croatica, 58(3), pp. 50815. [DOI:10.20471/acc.2019.58.03.15] [PMID] [PMCID]

Sudha, G., Reddy, K. N., \& Reddy, B. K., 2011. Emotional distress in infertile couples: A cross- cultural study. Asia Pacific Journal 
of Social Sciences, 3(1), pp. 90-101. https:/ /scholar.google.com/ scholar?hl=en\&as_sdt $=0 \% 2 \mathrm{C} 5 \& \mathrm{q}=$ Emotional+distress $+\mathrm{in}+\mathrm{in}$ fertile + couples $\% 3 \mathrm{~A}+\mathrm{A}+$ cross -+ cultural + study $\& b t n G=$

Teimourpour, N., et al., 2015. [Investigation of the relationship between attachment styles and ego-strength with adjustment to infertility in women referring to Valie-Asr reproductive health research centre (Tehran Imam Khomeini Hospital) in 2014 (Persian)]. The Journal of Rafsanjan University of Medical Sciences, 14(1), pp. 15-24. http://journal.rums.ac.ir/article1-2386-en.html

Vernon, A., 2012. Cognitive and rational-emotive behavior therapy with couples: Theory and practice, Springer Science \& Business Media. London. [DOI:10.1007/978-1-4614-5137-2]

Vizheh, M., et al., 2013. Effect of counseling on quality of marital relationship of infertile couples: A Randomized, Controlled Trial (RCT) study. Archives of Gynecology and Obstetrics, 287(3), pp. 583-9. [DOI:10.1007/s00404-012-2595-9] [PMID]

Zare, E., Bahrami, N., \& Soleimani, M. A., 2014. [Comparison of self-esteem in fertile and infertile women (Persian)]. Iran Journal of Nursing, 27(90), pp. 14-21. [DOI:10.29252/ijn.27.90.91.14] 